\title{
Cáncer de cabeza y cuello. Su impacto en la historia de la humanidad
}

José Francisco Gallegos-Hernández*

Instituto Mexicano del Seguro Social, Centro Médico Nacional Siglo XXI, Hospital de Oncología, Departamento de Tumores de Cabeza y Cuello, Ciudad de México, México

\section{Resumen}

El cáncer epidermoide es el más frecuente en cabeza y cuello y sus primeras descripciones datan de la época faraónica. Ha impactado en la humanidad al afectar la productividad laboral, científica y cultural y, en ocasiones, ha influido en el derrotero de la historia. El cáncer de cabeza y cuello es más frecuente en países e individuos depauperados económicamente, sin embargo, puede afectar cualquier estrato socioeconómico; lo han padecido personajes conocidos, famosos, económicamente poderosos, intelectuales y artistas. El tratamiento del cáncer de cabeza y cuello ha sido motivo de controversia desde su descripción inicial hasta la actualidad. En la decisión terapéutica ha influido no solo el estadio del cáncer sino el entorno del paciente; en ocasiones, en un afán de disminuir la morbilidad derivada de los diversos tratamientos oncológicos, se han tomado decisiones erróneas que han implicado la pérdida de la vida del enfermo. Infortunadamente, en la actualidad seguimos viendo estas conductas. Se presenta una síntesis de casos de connotados personajes que presentaron este cáncer y se describe el impacto que ello implicó en la sociedad de ese momento.

PALABRAS CLAVE: Carcinoma epidermoide. Cabeza. Cuello. Historia de la medicina.

\section{Head \& neck cancer. Its impact on the history of mankind}

\section{Abstract}

Squamous cell carcinoma is the most common head and neck malignancy, and its first descriptions date from the pharaonic era. It has impacted humanity by affecting labor, scientific and cultural productivity and, sometimes, it has influenced the course of history. Head and neck cancer is common in economically impoverished countries and individuals; however, it can affect any socioeconomic stratum; it has been suffered by known, famous, economically powerful celebrities, intellectuals and artists. Head and neck cancer treatment has been controversial since its initial description up to the present day. Therapeutic decisions have been influenced not only by the stage but by the patient's environment and, sometimes, in an effort to reduce the morbidity resulting from the various oncological treatments, erroneous decisions have been made that have implied the loss of the patient's life; unfortunately, currently we continue to see these behaviors. A synthesis of cases of renowned celebrities that suffered from this cancer is presented, and the impact this implied in the society of their times is described.

KEY WORDS: Squamous cell carcinoma. Head. Neck. History of medicine.

Correspondencia:

*José Francisco Gallegos-Hernández

E-mail: gal61@ prodigy.net.mx

0016-3813/๑ 2019 Academia Nacional de Medicina de México, A.C. Publicado por Permanyer. Este es un artículo open access bajo la licencia CC BY-NC-ND (http://creativecommons.org/licenses/by-nc-nd/4.0/). 


\section{Introducción}

El carcinoma epidermoide originado en las mucosas de cabeza y cuello es el tumor maligno más frecuente de esa área; es considerado un problema de salud ya que afecta a personas en edad productiva. En ocasiones, las secuelas del tratamiento o de la propia neoplasia son devastadoras para el individuo y pueden dificultar e, incluso, imposibilitar la reintegración del paciente a su entorno socioeconómico. ${ }^{1}$

A pesar de los progresos en el conocimiento de la biología y factores pronóstico de esta neoplasia y de los avances en los métodos diagnósticos y terapéuticos, la mortalidad continúa siendo elevada debido al retraso en su identificación: se estima que 500000 nuevos casos son diagnosticados anualmente en el mundo, $60 \%$ en etapas locorregionalmente avanzadas, lo que implica una supervivencia aproximada de $50 \%$ a cinco años. ${ }^{2-4}$

El carcinoma epidermoide de cabeza y cuello es conocido desde tiempos inmemoriales y aunque existe evidencia de esta afección desde la época faraónica, no se le prestó atención hasta que cinco personajes la padecieron en diferentes momentos de la historia: el emperador Federico III de Alemania, los presidentes de Estados Unidos Ulysses Simpson Grant y Grover Cleveland, Sigmund Freud y el célebre músico y compositor operístico Giacomo Puccini, quien por este padecimiento dejó inconclusa la ópera Turandot. Fue así que se iniciaron los esfuerzos para el reconocimiento temprano de este cáncer y la búsqueda de la mejor alternativa terapéutica.

\section{Antecedentes históricos}

Los rastros más antiguos de carcinoma de cabeza y cuello se encontraron en momias egipcias que datan de 5000 años a. C.; en ellas se han identificado al menos tres casos de cáncer nasofaríngeo (endémico en la zona hasta la fecha) y tres de osteosarcoma maxilar.

En el Papiro de Ebers, escrito en el tiempo de Amenofis I, principios del siglo XVI a. C., se describe el caso de un cáncer en la mucosa de la encía inferior tratado con ablación tumoral con un instrumento metálico al rojo vivo. Se describen también numerosas traqueotomías para el manejo de tumores que bloqueaban la vía respiratoria. En los siglos I y II, los griegos Celso y Galeno reportaron diversos carcinomas en labio y lengua. Además, se han encontrado cráneos con lesiones en los senos paranasales en excavaciones de la época de la Roma imperial que datan de los siglos I a III de nuestra era.

A pesar de esas descripciones y hallazgos, los cánceres de cabeza y cuello pasaron desapercibidos y fueron poco mencionados en la historia, hasta que los personajes motivo del presente escrito fueron diagnosticados con esta enfermedad. ${ }^{5,6}$

\section{El cáncer de laringe del príncipe Federico}

Federico III de Hohenzollern, último emperador de Prusia, gran fumador de pipa, heredero al trono por 27 años, finalmente sucede a su padre como rey de Prusia y emperador alemán en marzo de 1888. En 1871, apoyado por el canciller Otto van Bismark, crea el Segundo Reich y favorece la unificación alemana y la adhesión del Territorio Imperial de Alsacia y Lorena en una fastuosa ceremonia celebrada en la galería de espejos del Palacio de Versalles.

En enero de 1887, siendo el primero en la línea de sucesión al trono y con 56 años de edad, sufre un resfriado que le provoca disfonía, la cual se hace atender hasta marzo de ese mismo año. El profesor Gerhardt, quien realiza el examen clínico, identifica "lesión polipoide en la cuerda vocal izquierda", por la que prescribe tratamiento sintomático, sin mejoría. Dos meses después, los doctores van Bergman y Todd sugieren una laringofisura (tirotomía media) para realizar una biopsia ante la sospecha de cáncer laríngeo. El médico del príncipe, el doctor Wegner, la princesa Victoria y la reina Victoria, (esposa y suegra del príncipe Federico) prefieren la opinión del doctor Morell Mackenzie, célebre laringólogo inglés, ${ }^{7}$ quien descarta la existencia de un cáncer y diagnostica "sífilis laríngea". La biopsia de la lesión se realiza por laringoscopia directa y es evaluada por el célebre histopatólogo Rudolf Virchow, ${ }^{8}$ quien reporta paquidermia; el tratamiento continúa siendo sintomático.

Debido a empeoramiento del cuadro clínico se efectúa otra biopsia, nuevamente negativa a cáncer. El doctor Mackenzie instituye tratamiento con baños de percloruro de fierro, sin embargo, la disfonía se incrementa y aparecen datos de dificultad respiratoria. En junio, los médicos palpan una adenopatía cervical; a pesar de la evidencia, Mackenzie niega que se trate de un cáncer de laringe, por lo que el cuadro queda a libre evolución. En febrero de 1888, 13 meses después de iniciarse la disfonía, el príncipe debe ser sometido a traqueotomía de urgencia. El procedimiento es cruento, los médicos deben introducir los dedos entre el tumor para abrir la tráquea, hay sangrado transoperatorio y el 
príncipe Federico casi muere; como secuela de la cirugía se forma un absceso cervical y periestomal que persiste hasta la muerte del gobernante.

El 9 de marzo de 1888 muere el emperador Guillermo I de Alemania y Federico III asciende al trono; el pueblo en las calles canta "el emperador ha muerto, viva el emperador moribundo". En los días siguientes a su coronación, el ahora emperador expulsa fragmentos de tumor por la traqueotomía, los cuales son analizados por Waldeyer y solo así se obtiene el resultado histológico, cáncer epidermoide de laringe. No obstante la evidencia, Mackenzie continúa sosteniendo su diagnóstico de laringitis. El progreso del padecimiento es acelerado y la cánula de traqueotomía se bloquea repetidamente debido a fragmentos de tumor, lo que ocasiona severos cuadros de dificultad respiratoria. Finalmente, en junio de 1888, 17 meses después de iniciarse la disfonía, el emperador muere debido a hemorragia masiva por la traqueotomía. A Federico III se le conoce como "el emperador de los 99 días".

La muerte del emperador implica un desastre para Alemania y para el mundo; Federico III era liberal, sin embargo, quien lo sucede, su hijo Guillermo II, autoritario e impulsivo, bloquea la política pacifista del canciller Otto von Bismarck y alienta el conflicto que desemboca en el Primera Guerra Mundial, que cuesta 2 millones de muertos a Alemania y 10 millones al mundo, y en la que 70 millones de seres humanos son movilizados al frente de batalla.

La primera laringectomía total había sido descrita en 1874 por Billroth; en Francia, la primera serie de pacientes laringectomizados fue detallada por Labbé en 1885. La técnica había sido descrita por estos dos autores y por Gluck en Alemania, por Périer en Francia y por Tapia en España, de tal forma que se conocía cómo proceder en el cáncer de laringe. Probablemente el manejo fue conservador ya que la mortalidad en la primera semana de la laringectomía total era de $40 \%$, con una supervivencia de solo $8.5 \%$ según lo reportado en una serie de 103 laringectomías reportadas por Wolfender en 1887. El caso del emperador centró la atención en el diagnóstico oportuno, los síntomas iniciales, las causas de la neoplasia y los errores cometidos en el diagnóstico y tratamiento. ${ }^{9,10}$ Paradójicamente, hasta la fecha aún se observan estos errores respecto al cáncer laríngeo.

\section{El general Grant y el cáncer de orofaringe}

Ulysses Simpson Grant es un general muy popular en Estados Unidos por ser jefe del Estado Mayor de las tropas de la Unión en la Guerra de Secesión y cuya victoria sobre el general Lee logra la paz en esa nación. Gran fumador de puros y cigarrillos desde los 23 años, es electo $18^{\circ}$ presidente de su país en 1869.

En junio de 1884, siete años después de dejar la presidencia, se queja de odinofagia y en octubre del mismo año, los doctores De Acosta y Douglas emiten el diagnóstico de cáncer de la orofaringe. El tumor invade la amígdala, el velo palatino y la base de la lengua, a la cual está fijo; se acompaña de adenopatías bilaterales en cuello. Se propone bucofaringectomía transmandibular, sin embargo, después de una reevaluación se descarta el procedimiento. El general se retira a escribir sus memorias y nueve meses después muere, en medio de la ruina económica, dolor neuropático, periodos de asfixia y hemorragias constantes de la cavidad oral.

La bucofaringectomía transmandibular fue descrita por los médicos tratantes del general Grant: Sands, Douglas y Shadry, sin embargo, por la hemorragia, infecciones de la herida quirúrgica y la etapa avanzada no se efectuó el procedimiento. En Francia, la bucofaringectomía transmandibular fue reportada en 1906 por Vallas y Latarjet, pero fue Dargent, en 1952, quien obtuvo mejores resultados con una selección cuidadosa de los pacientes. Finalmente, el procedimiento es popularizado en la década de 1950 por Hayes Martin en Nueva York, quien lo denominó operación COMANDO, debido al tipo de acceso combinado (oral y cervical), que recordaba al que llevaron a cabo los comandos canadienses en la batalla de Dieppe en la recién finalizada, en ese momento, Segunda Guerra Mundial. ${ }^{10-12}$

\section{El presidente Grover Cleveland y el cáncer de la cavidad oral, subsitio paladar duro}

Grover Cleveland -abogado, perteneciente al partido demócrata y considerado el padre de la ortodoxia financiera- es elegido como el $22^{\circ}$ presidente de Estados Unidos en 1884. Al inicio de su segundo periodo presidencial, nota un bulto en el paladar duro, motivo por lo cual acude al médico. Su caso ejemplifica la importancia del diagnóstico oportuno, del tratamiento adecuado y de la importancia de la resección de los tumores de la cavidad oral.

El doctor O'Reilly, médico de la Casa Blanca, al ver la lesión toma una muestra para biopsia, la cual es enviada en secreto a estudio; el reporte indica carcinoma epidermoide invasor. El presidente teme que al hacer público el diagnóstico se desate pánico 
financiero en Wall Street, por lo que decide tratarse en secreto. El gran salón de un yate privado anclado en Nueva York es adaptado como sala de operaciones. Debido a la corpulencia y el cuello corto del presidente, la anestesia debe hacerse combinada con óxido nitroso e inyecciones locales de cocaína. La resección abarca del primer premolar a la región intermaxilar, dura una hora y 45 minutos; la oquedad posquirúrgica es taponada con una mecha de yodo. La cirugía es realizada por el doctor Joseph Bryan, quien había publicado una revisión 250 maxilectomías (solo dos efectuadas por él). La evolución es adecuada y la prótesis de caucho sella perfectamente el sitio donde se llevó a cabo la cirugía, lo que permite adecuada deglución y articulación del lenguaje. El presidente fallece 15 años después por otras causas, sin haber tenido nunca una recaída.

La enfermedad del presidente Grover Cleveland se hizo pública en 1917 y gracias a su buena evolución se le dio importancia al tratamiento, seguimiento y rehabilitación de los pacientes sometidos a este tipo de intervenciones. ${ }^{10-14} E n 1980$ se reevaluó el caso y se concluyó que se trataba de un carcinoma verrucoso del paladar duro, lo que explica el buen pronóstico con una sola variedad terapéutica. ${ }^{15}$

\section{Giacomo Puccini}

Giacomo Antonio Domenico Michele Secondo Maria Puccini, el célebre compositor italiano, nace en 1858 en Luca, en la Toscana, Italia; ha sido considerado el más grande compositor de ópera de fines del siglo XIX y principios del XX. Entre sus obras célebres destacan Manon Lescaut, La bohème, Tosca, Madame Butterfly y Turandot, esta última inconclusa debido a la progresión del cáncer laríngeo de su autor. ${ }^{16}$

Puccini, intenso fumador de cigarrillos y habanos, consulta con diversos otorrinolaringólogos en febrero de 1924 por disfonía, otalgia, disfagia y odinofagia. El diagnóstico es "inflamación reumática de la garganta", por el que recibe tratamiento sintomático. En noviembre del mismo año nota pérdida de peso, incremento de la otalgia y que no puede cerrar el cuello de la camisa debido a crecimiento de los ganglios cervicales. En Florencia, Torregiani le diagnóstica "cáncer extrínseco supraglótico con el tamaño de una nuez"; en ese entonces, los carcinomas laríngeos son clasificados como intrínsecos (de lenta evolución y buen pronóstico) y extrínsecos (con ganglios palpables en cuello, agresivos y de mal pronóstico, por lo que la recomendación es dejar a los enfermos a libre evolución). La biopsia confirma carcinoma de células escamosas. ${ }^{10,16}$

Son varias las situaciones que influyen en la decisión del tratamiento que se sigue con Puccini: su calidad de músico connotado, la morbilidad que la laringectomía total conlleva en ese entonces, la duda de que pudiese beneficiarse de cirugía conservadora laríngea y el advenimiento de un tratamiento novedoso, la radiación, por la que se opta con la finalidad de evitar la mutilación. Puccini acude a Bruselas, donde se ubica el único centro europeo que ofrece la radiación..$^{17}$ Ledoux inicia el tratamiento con un "collar que contenía radio", respecto al cual Puccini indica: "me están crucificando como a Cristo, tengo un collar alrededor de la garganta que tiene radiación; es una tortura".

Días después, bajo anestesia local, Ledeux inserta siete agujas con radiación en el cuello del compositor, efectúa traqueotomía y coloca sonda nasogástrica; el procedimiento dura tres horas. Respecto a su estado, Puccini escribe: "siento como si tuviera bayonetas en la garganta. ¡Esto es horrible!”. Cuatro días después, Puccini presenta una hemorragia cataclísmica por la boca y la traqueotomía; muere el 29 de noviembre de 1924, al alba, lo que recuerda el final de su aria Nessun Dorma, cuando el príncipe Calaf canta All'alba, vincerò!

Puccini muere sin concluir la ópera Turandot, privando a la humanidad de un "finale" seguramente apoteósico. Las últimas dos escenas de Turandot fueron acabadas por Franco Alfano bajo la supervisión de Arturo Toscanini. La noche del estreno en la Scala, el propio Toscanini, quien dirigía la orquesta, interrumpió la interpretación donde el maestro había dejado la composición, se volvió al público y dijo: "Aquí finaliza la ópera, porque en este lugar murió el maestro".

El renombre del compositor y la novedad terapéutica del momento, la radiación, influyeron en que no se efectuara laringectomía total y disección de cuello como estaba indicado, aun cuando la técnica había sido descrita poco más de tres décadas antes y se tenía suficiente experiencia. . $^{10,16,18}$ La decisión terapéutica errónea probablemente se basó en diversos factores ajenos a la extensión de la neoplasia. Incluso en nuestros días, en neoplasias locorregionalmente avanzadas no es la mejor decisión conservar la laringe, a pesar de la novedad terapéutica de tratar con quimioterapia y radioterapia. En pleno auge de este tratamiento, se ha reportado que la mortalidad de los pacientes con cáncer de laringe se ha 
incrementado por causas no oncológicas, tal vez debido a complicaciones por el tratamiento. ${ }^{19}$

\section{Sigmund Freud y el cáncer de la cavidad oral y el macizo centrofacial}

De nacionalidad austriaca, nacido en Moravia, padre del psicoanálisis y gran consumidor habitual de habanos, Freud presenta a los 67 años de edad un tumor en el paladar duro. Es evaluado por el doctor Majek, quien trata de resecar el tumor, ${ }^{20}$ pero el procedimiento debe ser interrumpido por hemorragia importante. Solo se efectúa una biopsia, con la que identifica carcinoma epidermoide. Se aconseja radioterapia dada la "irresecabilidad" del tumor, el cual persiste a pesar de las radiaciones. El doctor Pischler efectúa inicialmente ligadura de la carótida externa, resección ganglionar y gran resección de la cavidad oral en la zona de la región intermaxilar y el velo palatino; el defecto es ocluido con un injerto del antebrazo. ${ }^{21}$

Además de radioterapia complementaria, a Freud se le aconseja vasectomía para "hacer más lento el envejecimiento". Posterior a la radioterapia se le coloca un obturador palatino de caucho, que en varias ocasiones es ajustado a la hendidura quirúrgica. En los siguientes 13 años, Freud es sometido a 32 operaciones con la finalidad de resecar focos de carcinoma en el paladar y el remanente maxilar; sufre destrucción del macizo centrofacial, tanto por el tumor como por el consumo habitual de cocaína. ${ }^{22}$ Finalmente, presenta progresión masiva tumoral al macizo centrofacial y orofaringe que le provoca la muerte en 1939.

Aunque en Freud se logró una supervivencia de 13 años, la neoplasia nunca desapareció. Nuevamente nos encontramos ante diferentes factores no oncológicos que influyen en la decisión terapéutica. Con la maxilectomía radical, descrita por Genzoul en Francia desde 1827, probablemente se hubiese logrado la exéresis radical del tumor, aunada a un adecuado control. Incluso, Ferguson ya había sustituido la vía original transoral por la transfacial (aún útil en nuestro días). En Sigmund Freud nunca se intentó esta vía, sin que se conozca la razón de esa decisión. ${ }^{10}$

\section{El impacto del cáncer de cabeza y cuello en otros personajes de la historia}

Los personajes mencionados sufrieron cáncer de cabeza y cuello; algunos de ellos fueron sometidos a mala praxis médica. Muchas otras celebridades han muerto debido a esta neoplasia, si bien el impacto de este hecho en el desarrollo de la humanidad no ha sido trascendente como en los casos referidos. Entre las más connotadas están las siguientes:

- John Steele, paracaidista de la 82a. División Aerotransportada que al descender en 1944 durante la Operación Overlord (el desembarco en Normandía) quedó suspendido en la cúpula de la iglesia de Saint Mère Eglise; salvó la vida al no poder participar en la batalla en la que la mayoría de sus compañeros murieron. Años después, en 1969, falleció por cáncer de laringe.

- Lana Turner, actriz americana célebre por innumerables películas, principalmente El cartero siempre llama dos veces, murió en 1992 por cáncer de hipofaringe y esófago cervical.

- Sylvia Kristel, actriz originaria de Utrech, Países Bajos, icono del cine erótico de las décadas de 1970 y 1980 por la película Emanuelle, falleció en 2012 a causa de cáncer de orofaringe relacionado con intenso tabaquismo.

- Jack Klugman, reconocido por interpretar al personaje protagónico de la serie televisa Dr. Quincy, murió por cáncer de laringe en 2012.

- Rusell Means, conocido por su papel en la película El último mohicano, pereció en 2012 debido a cáncer oral (lengua).

- René Houseman, quien fuera campeón mundial de fútbol con la selección de Argentina en 1978, falleció por cáncer de lengua en 2018.

- Juan de Borbón, padre del rey emérito de España, Juan Carlos de Borbón, murió por cáncer de laringe.

- Príncipe Tomohito, en la línea de sucesión del imperio japonés, falleció por cáncer laríngeo supraglótico asociado con alcoholismo.

- Aldous Huxley, escritor británico, célebre por su novela Un mundo feliz, murió por cáncer laríngeo.

- William Hanna, productor de Los Picapiedra entre otras series de dibujos animados, falleció por cáncer laríngeo.

- Jack Hawkins, actor británico famoso por sus actuación en Tierra de faraones y Lawrence de Arabia y recordado como Quinto Arrio en la película Ben-Hur de 1959, murió por cáncer laríngeo.

- Khaterine Hepburn, actriz, murió por cáncer orofaríngeo.

- Ed Sullivan, famoso por conducir el espectáculo televisivo que llevaba su nombre y donde 
presentó a los Beatles por primera vez en América, falleció por cáncer orofaríngeo.

- George Harrison, miembro de los Beatles e intenso fumador, desarrolló dos tumores primarios, broncogénico y de laringe; las complicaciones de este último acabaron con su vida.

- Sammy Davis Jr., actor, murió por cáncer de laringe.

- Babe Ruth, fumador habitual de habanos, murió por cáncer orofaríngeo. Impuso récord de home runs en las grandes ligas de béisbol en 1935, récord que fue roto hasta 1974 por Hank Aaron.

- Enrique de Prusia, hijo de Federico III, al igual que su padre murió de cáncer laríngeo asociado con el intenso hábito de fumar tabaco.

- Tito Vilanova, entrenador del Fútbol Club Barcelona, murió por cáncer parotídeo.

En años recientes a numerosos personajes públicos se les ha diagnosticado cáncer epidermoide de cabeza y cuello, aunque superviven al mismo:

- Michel Douglas, quien a partir del adecuado manejo de su cáncer orofaríngeo, controlado con quimioterapia y radioterapia, se ha convertido en un activista en pro de la detección oportuna de esta neoplasia.

- Edie van Halen, intérprete de rock, tuvo cáncer de lengua.

- Bruce Dickinson, vocalista del grupo de rock Iron Maiden, padeció cáncer de lengua.

- Charlie Watts, baterista de The Rolling Stones, tuvo cáncer de laringe.

- Val Kilmer, quien interpretara al protagonista de una de las películas de Batman, tuvo cáncer laríngeo.

\section{Conclusión}

El cáncer de cabeza y cuello ocupa actualmente el sexto lugar de todas las neoplasias. En México, entre 60 y $70 \%$ de los pacientes son diagnosticados en etapas avanzadas, en las que la supervivencia difícilmente supera $50 \%$ a cinco años, aun con todos los recursos terapéuticos disponibles. Las causas de ello son el desconocimiento de los pacientes de sus factores de riesgo, el menosprecio de los propios pacientes por los síntomas y signos incipientes como disfonía, úlceras bucales o sangrado oral y el desconocimiento de los médicos de primer contacto de los signos de alerta indicativos de referencia inmediata al especialista.

La mejoría de la supervivencia se logra, como en otras neoplasias, no con tratamientos más radicales o costosos, sino con el diagnóstico en etapas tempranas y la instauración de un esquema terapéutico (incluso no radical) que ofrezca mejor control oncológico y supervivencia.

A pesar de ser largamente conocida, como he descrito, en esta neoplasia se siguen cometiendo errores en el diagnóstico y en el tratamiento, como sucedió al emperador Federico III de Prusia y Giacomo Puccini.

\section{Bibliografía}

1. Gallegos-Hernández JF. El cáncer de cabeza y cuello. Factores de riesgo y prevención. Cir Ciruj. 2006;74:287-293.

2. Su X, Liu Q, Li J, Zhang C, Xue Z, He C, et al. The oncological outcome and influence of neoadjuvant chemotherapy on the surgery in the resectable and locally advanced oral squamous cell carcinoma. Cancer Manag Res. 2019;25:7039-7046.

3. Verdonck de Leew IM, Jansen F, Brakenhoff RH, Langendijck JA, Takes $\mathrm{R}$, de Jong $\mathrm{RJB}$, et al. Advancing interdisciplinary research in head and neck cancer through a multicenter longitudinal prospective cohort study: the NETherlands Quality of life and Blomedical Cohort (NET-QUBIC) data warehouse and biobank. BMC Cancer. 2019;19:765.

4. Cachin I. Perspectives on cancer of the head and neck. En: Myers E, Suen JY, editores. Cancer of the head and neck. EE.UU.: Churchill Livingstone; 1959

5. Mudry A. Surgical treatment of head and neck cancers in the ancient world. J Laryngol Otol. 2015;129:535-539.

6. Riccomi G, Minozzi S, Pantano W, Catalano P, Aringhieri G, Giuffra V. Paleopathological evidence of paranasal lesions: two cases of frontal sinus osteomata from Imperial Rome. Int J Paleopathol. 2018:20:60-64.

7. Hughes JP, Almeyda JS, Bull TR, Royal Society of Medicine Library. Morell Makenzie and Crown Prince Frederick: an unpublished manuscript from the Royal Society of Medicine Library. J Laryngol Otol. 2009;123:261-265.

8. Sedivy R. The malady of Emperor Frederick III and Virchow's diagnostic role. Wein Med Wochenschr. 2015;165:140-151.

9. Teschner M. Laryngology in the late $19^{\text {th }}$ century: using the treatment of Frederick III as an example. HNO. 2012 Nov;60(11):985-92. DOI: 10.1007/s00106-012-2542-X.

10. Marandas P. Les cancers des VADS dans l'histoire. Ann Française ORL Pathol Cervico-Fac. 2011;128:116-121.

11. Steckler RM, Shedd DP. General Grant: his physicians and his cancer. Am J Surg. 1976;132:508-514.

12. Nelson RB. The final victory of General U.S. Grant. Cancer. 1981; 47:433-436

13. Maloney W. Surreptitious surgery on Long Island Sound: the oral cancer of President Grover Cleveland. N Y State Dent J. 2010;76:42-45.

14. Cooper PH. Presidents Cleveland's palatal tumor. Arch Dermatol. 1986; $122: 747-748$

15. Brooks JJ, Enterline HT, Horatio T. The final diagnosis of President Cleveland's lesion. JAMA. 1980;244:1-25

16. Marchese-Ragona R, Marioni G, Staffieri A. The unfinished Turandot and Puccini's laryngeal cancer. Larungoscope 2004;114:911-914.

17. Tainmont J. Belgian fate of Giacomo Puccini (1858-1924). B-ENT. 2006;2:151-159.

18. Peschel R, Peschel E. Guilt-in the company of Puccini's doctor. Psychol Rep. 1990;66:267-271

19. Licitra L, Bonomo P, Sanguineti G, Bacigalupo A, Baldi GG, Valerini S, et al. Different view of larynx preservation evidence-based treatment recommendations. J Clin Oncol. 2018;36:1376-1377.

20. Adeyemo WL. Sigmund Freud: smoking habit, oral cancer and euthanasia. Niger J Med. 2004;13:189-195.

21. Romm S. The oral cancer of Sigmund Freud. Clin Plast Surg. 1983;10:709-714.

22. Trimarchi M, Bertazzoni G, Bussi M. The disease of Sigmund Freud: oral cancer or cocaine-induced lesion? Eur Arch Otorhinolaryngol. 2019;276:263-265. 